\title{
The comparison of the effect of innovative designed storing-restoring hybrid passive AFO versus posterior leaf spring AFO on ankle joint kinematic in drop foot patients: A case series using a single subject design
}

\author{
Ensieh Pourhoseingholi ${ }^{1}$, Mohammad Kamali*2 (D), Hassan Saeedi ${ }^{1}$, Maryam Jalali ${ }^{1}$
}

Received: 14 May 2019

Published: 21 Dec 2020

\begin{abstract}
Background: Drop foot syndrome is a disorder characterized by foot slapping after the initial contact and foot-dragging during the swing phase. Passive and hybrid passive ankle foot orthoses (AFOs) are often prescribed in these patients; however, the effects of these AFO designs on kinematic parameters during gait are unclear. The aim of this study was to compare the effect of innovative designed storing-restoring hybrid passive AFOs versus posterior leaf spring AFO on ankle joint kinematics in drop foot patients.

Methods: The present study was a case series where a single case and 3 cases with drop foot syndrome were recruited. This study was designed in 2 phases: the baseline phase with their PLS AFOs and an intervention phase in which innovative designed AFO were assessed. Each phase included 5 measurement sessions which were performed in 5 consecutive weeks. The celeration line method was used to detect the significant differences between the phases.

Results: The results of this study showed a significant increase in the kinematic angles parameters at the initial contact, the loading response, the mid stance, terminal stance, pre swing, initial swing, mid swing, and terminal swing with the innovative designed AFO than with PLS AFO $(\mathrm{p}<0.05)$.

Conclusion: The results of the present study suggested that use of the innovative designed AFO may have a positive effect on ankle joint kinematics parameters in people with drop foot.
\end{abstract}

Keywords: Drop foot, Ankle foot orthosis, Kinematics

Conflicts of Interest: None declared

Funding: None

*This work has been published under CC BY-NC-SA 1.0 license.

Copyright $\odot$ Iran University of Medical Sciences

Cite this article as: Pourhoseingholi E, Kamali M, Saeedi H, Jalali M. The comparison of the effect of innovative designed storing-restoring hybrid passive AFO versus posterior leaf spring AFO on ankle joint kinematic in drop foot patients: A case series using a single subject design. Med $J$ Islam Repub Iran. 2020 (21 Dec);34:173. https://doi.org/10.47176/mjiri.34.173

\section{Introduction}

Drop foot syndrome is characterized by foot slapping after the initial contact and foot-dragging during the swing phase (1). As a result, the range of motion, flexibility, and biomechanical relationships between segments, static/dynamic balances (2-4), postural control, and forward

Corresponding author: Dr Mohammad Kamali, kamali.mo@iums.ac.ir

1. Department of Orthotics \& Prosthetics, School of Rehabilitation Sciences, Iran University of Medical Sciences, Tehran, Iran

2. Rehabilitation Research Center, School of Rehabilitation Sciences, Iran University of Medical Sciences, Tehran, Iran propulsion are affected (5).

As an intervention, AFOs are widely used in these patients to improve biomechanical gait parameters (6).

Passive AFOs are generally prescribed as a relatively cheap, lightweight intervention in drop foot patients (7).

$\uparrow$ What is "already known" in this topic:

Different types of passive and hybrid passive ankle foot orthosis (AFO) are frequently used to improve gait deviations in drop foot patients. However, these AFOs have some limitations like inability to generate push off power and lack of inadequate moments.

$\rightarrow$ What this article adds:

In this study it was found that innovative hybrid passive designed AFO significantly improved ankle range of motion and kinematic and led to more efficient walking. 
These AFOs have some drawbacks; however, to overcome the downsides, these AFOs were developed and modified by adding extra elements, such as hinges, flexion stops, spring, oil damper, and one-way friction clutch, to create near normal behavior at the ankle joint $(2,8)$. To replace the function of dorsiflexor muscles, an important aim of these mechanical elements is to store energy at the initial contact to mid stance and restore this energy during the rest of the gait cycle (pre swing to terminal swing) $(2,8)$. On the other hand, AFOs should be developed so that they offer storing and restoring enough energy, with proper timing and control without limiting the desirable ankle motion (9).

This study presented an innovative design of AFO as an adaptive solution for the AFOs based on sufficient energy storage and restoring mechanism.

The objective of this study was to compare kinematic parameters of the innovative designed AFO with those of posterior leaf spring AFO in drop foot patients.

\section{Methods}

\section{Study design}

This study was conducted through a case series using a single subject A-B design with 2 phases of baseline and intervention.

\section{Participants}

Three cases with drop foot syndrome were recruited from Occupational Therapy Center, Rehabilitation School of Iran University of Medical Sciences, with the mean age of 58.2 years (SD: 12.1). The average time after drop foot diagnosis was 3.2 years, with central and peripheral nervous system damages confirmed by magnetic resonance imaging (MRI), for the first diagnosis. Participants' sex, age, height are reported in Table 1.

All patients completed and signed informed consent forms prior to the study, and the study protocol was approved by the medical ethics committee of Iran University of Medical Sciences. Each participant had a confirmed diagnosis of drop foot with any reason caused by central and peripheral nervous system disorders.

This study included adults who had drop foot and had the same body mass with a history of using PLS AFO and with more than 2 grades in dorsi and plantar flexion based on manual muscle testing and less than 2-degree spasticity according to the Modified Ashworth Scale (MAS) (10, 11).

The following patients were excluded: those with any spasticity or contracture in the lower limb of the non paretic side, using any other therapeutic method at the time of this study (10), having cardiovascular or respiratory problems, having limb deficiency or amputation, cognitive problems, multiple neuropathy, instability in standing and walking, severe visual or hearing impairment, and feeling uncomfortable or exhausted to continue the cooperation.

\section{Instruments}

At the start of the experiment, 10 portable accelerometer sensors were attached to participants' limb based on the instructions of the motion analysis in the lower limbs. These sensors were placed at the middle of the sacral region, middle thigh, legs, and feet $(12,13)$. The participants stood inactive on their 2 legs in an anatomic position for 20 seconds for the software calibration. Then, kinematic data were collected for the 10-minute trial.

\section{Measurement Procedure}

At the first session, patients were recruited according to the exclusion and inclusion criteria.

For the baseline measurements, patients were asked to walk at their comfortable, self-selected speed across the laboratory with their own shoes and PLS. This procedure was repeated in 5 sessions every week. Before the intervention phase, innovative designed AFO was constructed and fitted for 4 weeks as a weaning time. Then, an intervention measurement was also performed with the same condition as the base line session.

Motion capture system (Noraxon 2013, USA) equipped with Internal Measurement Unit sensors (IMU) was employed to collect kinematics data performed in sagittal direction at a sampling rate of $100 \mathrm{~Hz}$. Biomechanical inverse dynamics model was used to calculate joint angles. This way, kinematics (joint angles) data were recorded. Motion data were low-pass filtered at $14 \mathrm{~Hz}$ and 39 $\mathrm{Hz}$, respectively, using fourth-order, zero-lag, and Butterworth filters determined by the residual analysis method as described by Winter (14-16).

\section{Innovative designed storing-restoring hybrid passive} AFO

The innovative designed AFO with storing restoring element was designed and constructed with a mechanical component to replace the function of dorsiflexor muscles.

This innovative designed AFO composed of 2 separate carbon composite sections linked together by a side bar to establish the attachment for actuator mechanism.

The actuator mechanism was composed of modifiable springs and adjustable hydraulic shock absorbers (Ecooem1.0mm-Eco-oem5.0mm). When the actuator mechanism was compressed, it stored energy, then returned to its rest configuration, where the energy was released to provide resistance and assistance moment at the ankle joint.

Foot section structure was first created from polypropylene. Due to some reasons, like weight loss and improved flexibility at the foot section, the mechanical building was revised and a new structure was planned to be

Table 1. Demographic information of the participants

\begin{tabular}{lcccc}
\hline Participants & Gender & $\begin{array}{c}\text { Age } \\
\text { (years) }\end{array}$ & $\begin{array}{c}\text { Weight } \\
\text { (kilogram) }\end{array}$ & $\begin{array}{c}\text { Height } \\
\text { (centimeters) }\end{array}$ \\
\hline Subject 1 & Male & 62 & 85 & 178 \\
Subject 2 & Male & 58 & 80 & 175 \\
Subject 3 & Female & 52 & 67 & 2 \\
\hline
\end{tabular}


built from flexible carbon composite.

However, the shank and cuff portion should have not been placed medially and laterally. To achieve this goal, a stainless-steel articulation was placed at the back of the AFO without limiting or interfering ankle joint, which slightly protruded the posterior part from patients' dress. The cuff section was completely covered with neoprene for more comfort. This was the main way to reduce the size of the AFO and to facilitate the fitting process of shoe fitting for clinicians. We also could design an adjustable slider in front of the shank cuff, which could be moved up and down on the rail to compensate for the differential motion between AFO and paretic limb.

\section{Statistical analysis}

Split middle approach was used to develop celeration line in both baseline and intervention phase $(17,18)$. To evaluate the difference between the phases, trend of celeration lines, slop and level of changes in each condition were used. The statistically significant difference between the 2 groups were obtained by extending the celeration line for the baseline phase into the intervention phase and by evaluating the distribution of the scores above or below the line in the intervention phase via the one-tailed binom- inal test (18).

Significance level was set at 0.05 . According to the one-tailed binominal test, the difference between the 2 phases was statistically significant at 0.05 when all 5 points in intervention phase were either below or above the extension of the baseline phase celeration line (17).

\section{Results}

The demographic results of the 3 patients are summarized in Table 1. All of the variables were analyzed with the celeration line and its trend, slop and level of difference. Figures show the kinematic changes for the participants.

Ankle kinematic parameters of drop foot patients 5 sessions of the base line phase with PLS and 5 sessions of intervention phase with innovative designed AFO are shown in Table 2 and Figures 1-4.

The comparison of the intervention phase and the baseline phase showed a significant increase in the kinematic parameters $(\mathrm{p}<0.05)$ in all participants. These parameters in the baseline phase were significantly lower than that in the intervention phase (Tables 2,3).

\begin{tabular}{|c|c|c|c|c|c|c|c|c|c|}
\hline \multirow[t]{2}{*}{ AFOs } & \multirow[t]{2}{*}{ Phases } & \multicolumn{8}{|c|}{ Subject 1} \\
\hline & & $\mathrm{IC}$ & $\overline{L R}$ & MST & $\overline{\text { TST }}$ & PSW & ISW & MSW & $\overline{\text { TSW }}$ \\
\hline \multirow[t]{5}{*}{ PLS } & Week 1 & 5.1 & -10.3 & 5.6 & 5.6 & -22.1 & -10.2 & -2.6 & -2.5 \\
\hline & Week 2 & 5.2 & -10.3 & 5.8 & 5.7 & -21.1 & -10.5 & -2.8 & -2.4 \\
\hline & Week 3 & 5.1 & -10.4 & 5.7 & 5.7 & -21.3 & -10.3 & -2.4 & -2.3 \\
\hline & Week 4 & 5.4 & -10.2 & 5.9 & 5.8 & -22.2 & -10.2 & -2.3 & -2.4 \\
\hline & Week 5 & 5.2 & -10.4 & 5.7 & 5.9 & -21.1 & -10.3 & -2.5 & -2.4 \\
\hline \multirow[t]{5}{*}{ Innovative AFO } & Week 1 & -5.1 & -16.1 & 7.1 & 9.4 & -26.6 & -15.8 & 2.6 & 0 \\
\hline & Week 2 & -5.1 & -15.6 & 7.2 & 9.8 & -25.3 & -15.8 & 3.1 & 0 \\
\hline & Week 3 & -5.1 & -15.6 & 8.7 & 10.2 & -24.4 & -15.6 & 3.2 & 0 \\
\hline & Week 4 & -5.1 & -14.8 & 8.9 & 10.4 & -23.7 & -15.8 & 3.3 & 0 \\
\hline & Week 5 & -5.1 & -14.3 & 9.3 & 10.6 & -23.1 & -15.2 & 3.6 & 0 \\
\hline \multirow[t]{2}{*}{ AFOs } & Phases & \multicolumn{8}{|c|}{ Subject 2} \\
\hline & & $\mathrm{IC}$ & LR & MST & TST & PSW & ISW & MSW & TSW \\
\hline \multirow[t]{5}{*}{ PLS } & Week 1 & 0 & -3.6 & 11.6 & 13.6 & -4.8 & -3.6 & -2.4 & 5.2 \\
\hline & Week 2 & 0 & -3.8 & 11.9 & 13.8 & -4.5 & -3.4 & -2.3 & 5.2 \\
\hline & Week 3 & 0.3 & -3.6 & 11.8 & 13.8 & -4.8 & -3.2 & -2.3 & 5.2 \\
\hline & Week 4 & 0.4 & -3.8 & 11.7 & 13.8 & -4.7 & -3.2 & -2.3 & 5.2 \\
\hline & Week 5 & 0.5 & -3.6 & 11.8 & 13.9 & -4.5 & -3.2 & -2.3 & 5.2 \\
\hline \multirow[t]{5}{*}{ Innovative AFO } & Week 1 & 0 & -8.7 & 16.1 & 17.6 & -25.9 & -21.6 & 2.1 & 5.6 \\
\hline & Week 2 & -1.4 & -7.7 & 17.8 & 18.8 & -24.7 & -20.1 & 2.4 & 0 \\
\hline & Week 3 & 0 & -6.9 & 19.2 & 21.1 & -22.4 & -19.6 & 3.2 & 0 \\
\hline & Week 4 & 0 & -6.4 & 21.4 & 23.4 & -21.6 & -19.1 & 3.8 & 0 \\
\hline & Week 5 & 0 & -5.4 & 21.3 & 24.8 & -21.3 & -18.4 & 4.1 & 0 \\
\hline \multirow[t]{2}{*}{ AFOs } & Phases & \multicolumn{8}{|c|}{ Subject 3} \\
\hline & & $\mathrm{IC}$ & LR & MST & TST & PSW & ISW & MSW & TSW \\
\hline \multirow[t]{5}{*}{ PLS } & Week 1 & -2.5 & 5.1 & -10.4 & 5.4 & -22.3 & -10.3 & -2.7 & -2.5 \\
\hline & Week 2 & -2.5 & 5.2 & -10.3 & 5.5 & -22.2 & -10.3 & -2.6 & -2.5 \\
\hline & Week 3 & -2.5 & 5.2 & -10.2 & 5.5 & -22.2 & -10.2 & -2.5 & -2.5 \\
\hline & Week 4 & -2.5 & 5.2 & -10.2 & 5.6 & -22.1 & -10.2 & -2.5 & -2.5 \\
\hline & Week 5 & -2.5 & 5.2 & -10.2 & 5.8 & -22.1 & -10.1 & -2.5 & -2.5 \\
\hline \multirow[t]{5}{*}{ Innovative AFO } & Week 1 & 0 & 3.4 & -18.6 & 18.3 & -29.8 & -23.1 & 2.4 & 0 \\
\hline & Week 2 & 0 & 3.5 & -17.5 & 19.6 & -27.8 & -22.8 & 2.6 & 0 \\
\hline & Week 3 & 0 & 3.6 & -17.8 & 20.8 & -26.7 & -22.6 & 2.6 & 0 \\
\hline & Week 4 & 0 & 3.7 & -16.3 & 21.3 & -25.6 & -22.3 & 2.8 & 0 \\
\hline & Week 5 & 0 & 3.8 & 21.2 & 24.1 & -24.8 & -21.2 & 3.2 & 0 \\
\hline
\end{tabular}

IC: Initial contact, LR: Loading response, MST: Mid stance, TST: Terminal stance, PSW: Pre swing, ISW: Initial swing, MSW: Mid swing, TSW: Terminal swing. In this table, + was used for means dorsi flexion and - was used for plantar flexion. 


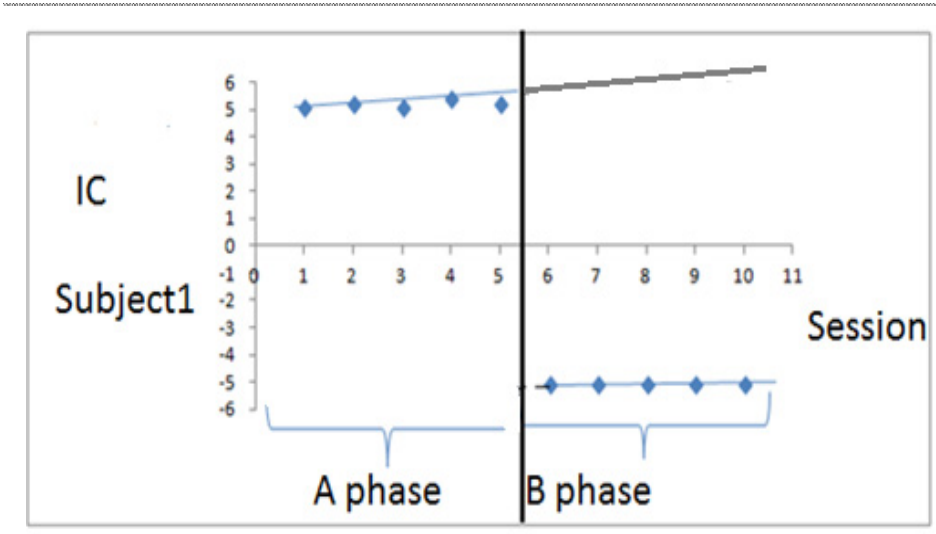

Fig. 1. Kinematic changes of initial contact ankle angle in subject 1

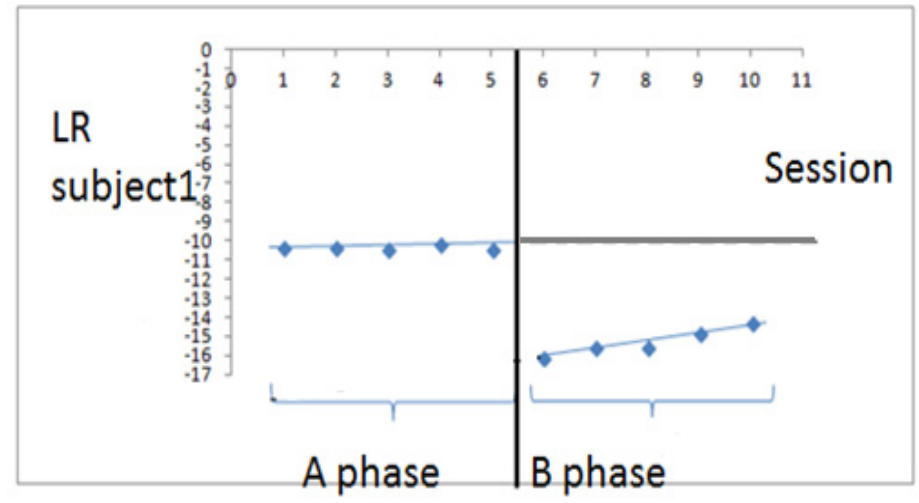

Fig. 2. Kinematic changes of peak of plantar flexion in loading response in subject 1

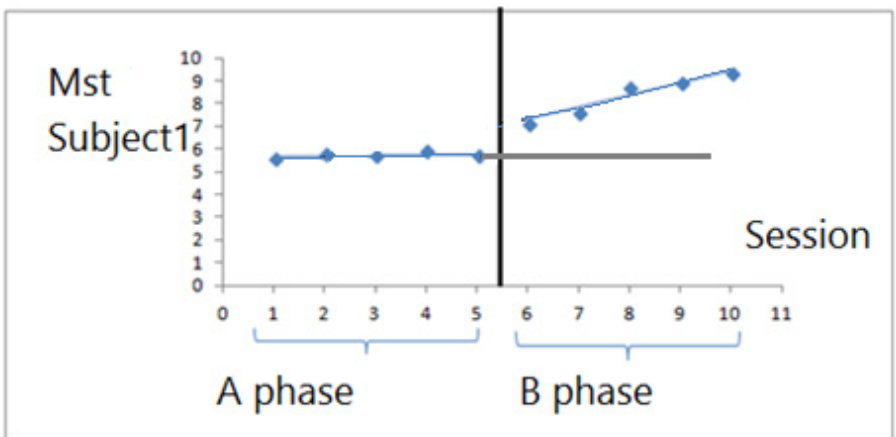

Fig. 3. Kinematic changes of peak of dorsi flexion in mid stance in subject 1

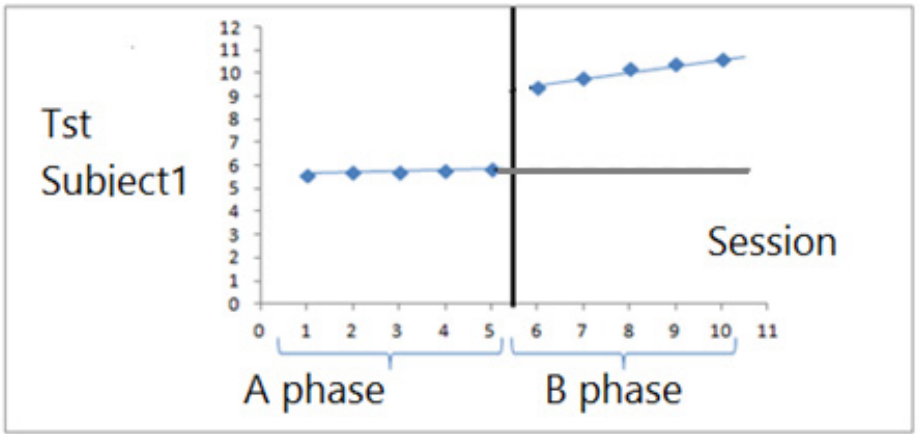

Fig. 4. Kinematic changes of peak of dorsi flexion in the terminal stance in subject 1

\section{Discussion}

$4 \quad$ http://mjiri.iums.ac.ir

Med J Islam Repub Iran. 2020 (21 Dec); 34:173. 
Table 3. Results of celeration line and its trend, level, slope, and variability methods, and intervention compared with the baseline phase

\begin{tabular}{|c|c|c|c|c|c|c|c|c|c|c|c|c|}
\hline \multirow{3}{*}{$\begin{array}{l}\text { Kinematic } \\
\text { parameters }\end{array}$} & \multicolumn{4}{|c|}{ Subject 1} & \multicolumn{4}{|c|}{ Subject 2} & \multicolumn{4}{|c|}{ Subject 3} \\
\hline & \multicolumn{2}{|c|}{ Slope } & \multirow[t]{2}{*}{$\mathrm{p}$} & \multirow{2}{*}{$\begin{array}{c}\text { Level } \\
\text { diff }\end{array}$} & \multicolumn{2}{|c|}{ Slope } & \multirow[t]{2}{*}{$\mathrm{p}$} & \multirow{2}{*}{$\begin{array}{c}\text { Level } \\
\text { diff }\end{array}$} & \multicolumn{2}{|c|}{ Slope } & \multirow[t]{2}{*}{$\mathrm{p}$} & \multirow{2}{*}{$\begin{array}{c}\text { Level } \\
\text { Diff }\end{array}$} \\
\hline & Phase1 & Phase2 & & & Phase1 & Phase2 & & & Phase1 & Phase2 & & \\
\hline Initial contact & 0.05 & 0.00 & 0.05 & 10.5 & 0.12 & 0.00 & 0.119 & 0.5 & 0.02 & 0.1 & 0.05 & 1.8 \\
\hline Loading response & 0.05 & 0.45 & 0.05 & 5.7 & -0.05 & 0.82 & 0.05 & 5.1 & 0.05 & 0.08 & 0.05 & 8.4 \\
\hline Mid stance & 0.07 & 0.55 & 0.05 & 1.2 & 0.07 & 1.3 & 0.05 & 4.2 & 0.05 & 1.02 & 0.05 & 11.5 \\
\hline Terminal stance & 0.07 & 0.3 & 0.05 & 3.5 & 0.07 & 1.8 & 0.05 & 3.7 & 0.05 & 1.4 & 0.05 & 12.50 \\
\hline Pre swing & 0.27 & 0.87 & 0.05 & 3.5 & 0.07 & 1.15 & 0.05 & 21.4 & 0.05 & 1.27 & 0.05 & 7.7 \\
\hline Initial swing & 0.07 & 0.15 & 0.05 & 5.6 & 0.1 & 0.8 & 0.05 & 18.4 & 0.05 & 0.57 & 0.05 & 13 \\
\hline Mid swing & 0.12 & 0.25 & 0.05 & 5.7 & 0.2 & 0.5 & 0.05 & 4.4 & 0.05 & 0.2 & 0.05 & 4.9 \\
\hline Terminal swing & 0.05 & 0.00 & 0.05 & 2.5 & 0.00 & 0.00 & 0.05 & 5.2 & 0.00 & 0.00 & 0.05 & 2.5 \\
\hline
\end{tabular}

(Level diff): The differences between the termination of phase 1 (baseline phase) celeration line and initiation of phase 2 (intervention) celeration line; (initiation of phase 2 celeration line) - (termination of phase 1 celeration line)

(Sig.): significances

$(*)$ : the difference is significant at the 0.05 level, when comparing phase 1 vs phases 2 .

This study involved a case series using a single subject design study performed over a 10-week trial to extract kinematic outcome measures at the ankle joint as the most involved joint, while transforming drop foot patients from polypropylene posterior leaf spring (PLS) AFO to innovative designed AFO.

According to results of this study, the ankle angle at the initial contact, the peak angle at the loading response, the mid stance, terminal stance, the pre swing, initial swing, mid swing, and terminal swing were significantly improved with innovative designed AFO than with PLS. Due to dorsi flexor weakness in the affected limb, the overall ROM at the ankle joint was reduced during the early through terminal stance (19). According to this study, the overall ROM in the ankle joint was decreased with the base line PLS AFO than the innovative designed AFO, which was confirmed in other studies $(19,20)$.

Expectedly and as extensively observed in these patients, with excessive function of the antagonistic muscles, the ankle agonist muscles are unable to put the ankle joint in a neutral position (21).

Both AFOs (PLS and innovative designed AFO) improved the initial contact angle to near neutral in these patients, which is probably due to the adjustment of the ankle angle in the neutral or slightly dorsi flexion, which was confirmed with other types of passive and dynamic AFOs $(22,23)$.

Putting the ankle at neutral position in this phase decreased the need for compensatory mechanisms, encouraging the limb advancement toward the loading response, absorbing the shock from the initial contact, improving the ability to control the ankle complex at the early stance, and preventing excessive knee flexion in the mid stance, and enhancing the overall dynamic stability.

Our findings suggested that the innovative designed AFO significantly improved the peak plantar flexion angle at loading response than PLS.

If PLS or any other type of AFOs reduces this peak (24-26), excessive flexion in the knee and sometimes in the hip increases the likelihood of instability or risk of buckling at the knee joint $(20,26,27)$.

The findings of this study indicated that the innovative designed AFO significantly enhanced the peak angle of dorsiflexion at mid stance compared to PLS, which was confirmed by other studies in which hybrid passive or dynamic AFOs significantly elevated the dorsiflexion peak than PLS $(8,28-30)$. Since this innovative designed AFO improved this peak, the need to use hip or knee extension as a compensatory mechanism to move the center of gravity and forward propulsion was decreased $(5,31$, 32).

In line with some studies, the findings of the present study revealed the innovative designed AFO significantly improved the peak dorsiflexion in the terminal stance in comparison to PLS.

Therefore, improvement in this peak may improve tibia advancement (33), may aid in third rocker, may ameliorate the dynamic stability (26), and may also increase the step length and speed $(34,35)$.

In various studies, reduction in the dorsiflexion peak in the mid to terminal stance has been a major disadvantage of passive hybrid AFO $(23,28)$ resulting in inability to forward propulsion $(33,36,37)$, insufficient loading (31), reduction in preparation for initial contact, inability to climb ramp and stairs, decreased power production capacity in the pre swing, decreased speed (36), and step length as well as instability in this phase (32).

The findings of this study showed the peak of plantar flexion in the pre swing significantly increased with innovative designed AFO compared to PLS. The possible cause of reduction of this peak with PLS AFO is the diminished range of motion in this phase $(27,38)$.

Therefore, the innovative designed AFO can lead to better propulsion of the limb into the swing phase and prevent quick, premature, and incomplete movement of the limb towards the swing phase, improve balance, reduce energy loss, lengthen the stance phase, and increase the push off power $(35,39-41)$.

According to this study, both AFOs improve the ankle angle at the swing phase, especially in the mid swing through the next initial contact, which was confirmed in other studies $(20,23,29)$.

The authors acknowledge some limitations of this study. One of the limitations was not considering the kinetics of the ankle joint as well as interaction and synergy of the kinetic and kinematic parameters. The results of this study demonstrated that the use of AFOs modifies kinematic patterns of gait. Although the sample size was reasonably 
large, studies with a larger number of individuals and different types of AFO are required.

\section{Conclusion}

Innovative designed AFO improved the ankle kinematic parameters of drop foot patients to cope with different aspects of this disorder and provide a chain of improvements within the ankle. The findings of this study helped to explain the gait abnormalities resulting from impaired function and to further understand the effects of AFO interventions.

\section{Acknowledgment}

The authors wish to express their sincere gratitude to Miss Afsane Mohammad pour for her assistance throughout this study.

\section{Conflict of Interests}

The authors declare that they have no competing interests.

\section{References}

1. Simonsen EB, Moesby LM, Hansen LD, Comins J, Alkjaer T. Redistribution of joint moments during walking in patients with dropfoot. Clin Biomech. 2010;25(9):949-52.

2. Alam M, Choudhury IA, Mamat AB. Mechanism and design analysis of articulated ankle foot orthoses for drop-foot. Sci World J. 2014;2014.

3. Guigon E, Baraduc P, Desmurget M. Computational motor control: redundancy and invariance. J Neurophysiol. 2007;97(1):331-47.

4. Michalina B, Ida W, Katarzyna K, Brzuszkiewicz-Kuźmicka G, Andrzej W. Mechanisms of compensation in the gait of patients with drop foot. Clin Biomech. 2017;42:14-9.

5. Simons CD, van Asseldonk EH, van der Kooij H, Geurts AC, Buurke JH. Ankle-foot orthoses in stroke: effects on functional balance, weight-bearing asymmetry and the contribution of each lower limb to balance control. Clin Biomech. 2009;24(9):769-75.

6. Tyson SF, Kent RM. Effects of an ankle-foot orthosis on balance and walking after stroke: a systematic review and pooled meta-analysis. Arch Physic Med Rehabil. 2013;94(7):1377-85.

7. Amerinatanzi A, Zamanian H, Moghaddam NS, Ibrahim H, Hefzy MS, Elahinia M, editors. On the advantages of superelastic Niti in ankle foot orthoses. ASME 2016 Conference on Smart Materials, Adaptive Structures and Intelligent Systems; 2016: American Society of Mechanical Engineers.

8. Mulroy SJ, Eberly VJ, Gronely JK, Weiss W, Newsam CJ. Effect of AFO design on walking after stroke: impact of ankle plantar flexion contracture. Prosthet Orthot Int. 2010;34(3):277-92.

9. Amerinatanzi A, Zamanian H, Shayesteh Moghaddam N, Jahadakbar A, Elahinia M. Application of the Superelastic NiTi Spring in Ankle Foot Orthosis (AFO) to Create Normal Ankle Joint Behavior. Bioengineering. 2017;4(4):95.

10. Kim ES, Yoon YS, Sohn MK, Kwak SH, Choi JH, Oh JS. Effect of pneumatic compressing powered orthosis in stroke patients: preliminary study. Ann Rehabil Med. 2015;39(2):226.

11. Delafontaine A, Gagey O, Colnaghi S, Do MC, Honeine JL. Rigid ankle foot orthosis deteriorates mediolateral balance control and vertical braking during gait initiation. Front Hum Neurosci. 2017;11:214.

12. Collins TD, Ghoussayni SN, Ewins DJ, Kent JA. A six degrees-offreedom marker set for gait analysis: repeatability and comparison with a modified Helen Hayes set. Gait Posture. 2009;30(2):173-80.

13. Willer CJ, Speliotes EK, Loos RJ, Li S, Lindgren CM, Heid IM, et al. Six new loci associated with body mass index highlight a neuronal influence on body weight regulation. Nature Gene. 2009;41(1):25.

14. Winter DA. Biomechanics and motor control of human movement: John Wiley \& Sons; 2009.

15. Żuk M, Pezowicz C. Kinematic analysis of a six-degrees-of-freedom model based on ISB recommendation: a repeatability analysis and comparison with conventional gait model. Appl Bionics Biomech. 2015;2015

16. Neves MC. Design of Ankle Foot Orthoses using Subject Specific Biomechanical Data and Optimization Tools. 2014.

17. Mercer VS, Chang SH, Williams CD, Noble KJ, Vance AW. Effects of an exercise program to increase hip abductor muscle strength and improve lateral stability following stroke: a single subject design. J Geriatr Physic Ther. 2009;32(2):6-15.

18. Ottenbacher KJ. Evaluating clinical change: Strategies for occupational and physical therapists: Williams \& Wilkins; 1986.

19. Błażkiewicz M, Wiszomirska I, Kaczmarczyk K, BrzuszkiewiczKuźmicka G, Wit A. Mechanisms of compensation in the gait of patients with drop foot. Clin Biomech. 2017;42:14-9.

20. Bregman D, Harlaar J, Meskers C, De Groot V. Spring-like Ankle Foot Orthoses reduce the energy cost of walking by taking over ankle work. Gait Posture. 2012;35(1):148-53.

21. Ries A. Evaluating and Improving the Efficacy of Ankle Foot Orthoses for Children with Cerebral Palsy. Retrieved from the University of Minnesota Digital Conservancy, http://hdl.handle.net/11299/185580..

22. Leardini A, Aquila A, Caravaggi P, Ferraresi C, Giannini S. Multisegment foot mobility in a hinged ankle-foot orthosis: the effect of rotation axis position. Gait Posture. 2014;40(1):274-7.

23. Bleyenheuft C, Caty G, Lejeune $T$, Detrembleur C, editors. Assessment of the Chignon ${ }^{\circledR}$ dynamic ankle-foot orthosis using instrumented gait analysis in hemiparetic adults. Annales de réadaptation et de médecine physique; 2008: Elsevier.

24. Abdollahi Sofla M. Identification, simulation and control of an ankle foot orthosis: University of Toledo; 2012.

25. Pittaccio S, Viscuso S. An EMG-controlled SMA device for the rehabilitation of the ankle joint in post-acute stroke. J Mat Engin Perform. 2011;20(4-5):666-70.

26. Wach A. Mechanical Characterization of Carbon Fiber and Thermoplastic Ankle Foot Orthoses. epublications.marquette.edu. 2015.

27. Wiggin MB. Characterizing Optimal Performance of a Passive Elastic Ankle Exoskeleton during Human Locomotion: North Carolina State University; 2014.

28. Yamamoto S, Ibayashi S, Fuchi M, Yasui T. Immediate-term effects of use of an ankle-foot orthosis with an oil damper on the gait of stroke patients when walking without the device. Prosthet Orthot Int. 2015;39(2):140-9.

29. Yamamoto S, Fuchi M, Yasui T. Change of rocker function in the gait of stroke patients using an ankle foot orthosis with an oil damper: immediate changes and the short-term effects. Prosthet Orthot Int. 2011;35(4):350-9.

30. Yamamoto S, Tomokiyo N, Yasui T, Kawaguchi T. Effects of plantar flexion resistive moment generated by an ankle-foot orthosis with an oil damper on the gait of stroke patients: a pilot study. Prosthet Orthot Int. 2013;37(3):212-21.

31. Bregman DJJ. The optimal ankle foot orthosis: the influence of mechanical properties of Ankle Foot Orthoses on the walking ability of patients with central neurological disorders. 2011.

32. Eamer L. Redesign of Ankle Foot Orthoses for Increased Stability and Mobility: University of Toronto; 2008.

33. Burnfield JM, Shu Y, Buster T, Taylor A. Similarity of joint kinematics and muscle demands between elliptical training and walking: implications for practice. Physic Ther. 2010;90(2):289-305.

34. Wiszomirska I, Błażkiewicz M, Kaczmarczyk K, BrzuszkiewiczKuźmicka G, Wit A. Effect of drop foot on spatiotemporal, kinematic, and kinetic parameters during gait. Appl Bionics Biomech. 2017;2017.

35. Rogozinski B, Schwab S, Kesar T. Effects of an Articulated Ankle Foot Orthosis on Gait Biomechanics in Adolescents with Traumatic Brain Injury: A Case-Series Report. Physic Med Rehabil Int. 2018;5(2).

36. Koller CA. Effect of quantitatively matched passive-dynamic anklefoot orthoses on post-stroke gait: University of Delaware; 2018.

37. Haight DJ, Esposito ER, Wilken JM. Biomechanics of uphill walking using custom ankle-foot orthoses of three different stiffnesses. Gait Posture. 2015;41(3):750-6.

38. Gregorczyk KN, Hasselquist L, Schiffman JM, Bensel CK, Obusek JP, Gutekunst DJ. Effects of a lower-body exoskeleton device on metabolic cost and gait biomechanics during load carriage. Ergonomics. 2010;53(10):1263-75.

39. Matinmanesh A, Mallakzadeh $\mathrm{M}$, editors. Inverse kinetic and 
kinematic analysis of drop-foot patient's walking. 2011 E-Health and Bioengineering Conference (EHB); 2011: IEEE.

40. Allen JL, Kautz SA, Neptune RR. Forward propulsion asymmetry is indicative of changes in plantarflexor coordination during walking in individuals with post-stroke hemiparesis. Clin Biomech. 2014;29(7):780-6.

41. Azevedo ERFBMd, Cacho EWA, Alonso KC, Martin FTB, Cliquet Jr A, editors. Kinetic and Kinematic Gait Assessment of Paraplegic Patients with and without Ankle Foot Orthoses. Biodevices; 2010. 